\title{
Exergetic Analysis of a Refrigeration System with Mechanical Vapors Compression
}

\author{
Louis Okotaka Ebale ${ }^{1}$, Aristide H. W. Nakavoua ${ }^{2}$, Landry Jean Pierre Gomat ${ }^{1}$ \\ ${ }^{1}$ Laboratory of Mechanics, Energetics and Engineering, Unesco Chair in Engineering Sciences Ecole Nationale Supérieure \\ Polytechnique, Marien Ngouabi University, Brazzaville, Congo \\ ${ }^{2}$ Laboratory of Chemistry of Natural Substances (IRSEN), Brazzaville, Congo \\ Email: ^dajlouis@yahoo.fr
}

How to cite this paper: Ebale, L.O., Nakavoua, A.H.W. and Gomat, L.J.P. (2020) Exergetic Analysis of a Refrigeration System with Mechanical Vapors Compression. Energy and Power Engineering, 12, 490-498. https://doi.org/10.4236/epe.2020.128030

Received: July 7, 2020

Accepted: August 25, 2020

Published: August 28, 2020

Copyright (c) 2020 by author(s) and Scientific Research Publishing Inc. This work is licensed under the Creative Commons Attribution International License (CC BY 4.0).

http://creativecommons.org/licenses/by/4.0/

\begin{abstract}
The main purpose of this study is to improve the energy efficiency of a refrigerated facility by means of exergetic analysis. In order to achieve this goal, we have evaluated the input exergy flows of the whole system to deduce the exergetic yields, which are compared to the degree of irreversibility in order to have a qualitative measurement of energy losses. The concept of exergy is the part of energy that is virtually converted into work. The exergetic analysis was performed on a refrigeration unit ZR22K3E Copeland Scroll. The results of this analysis are consistent with the condition, that the exergetic performance, which is: $36.57 \%$ and it is approximately equal to the degree of irreversibility which is $37.50 \%$. This approach provides a comprehensive, standard and rigorous framework for the analysis of energy systems, and thus for the understanding and systemic management of the energy challenge.
\end{abstract}

\section{Keywords}

Exergy, Exergetic Balance, Exergetic Performance

\section{Introduction}

Nowadays, cold production has a significant impact on the environment. It represents $8 \%$ of global greenhouse gas emissions, $80 \%$ are due to energy consumption by refrigeration on facilities and $20 \%$ are released by refrigerants into the atmosphere [1]. In the context of pressure on energy resources, energy reduction is a crucial issue, mainly on the current problems related to the rational use of energy and environmental conservation. The cold and heat production has constrained thermodynamic (minimization of irreversibility by limiting the 
pinches to the exchangers, load losses, overheating), etc. [2] [3] [4] [5] [6]. Radcenco and Canivet show that the exergetic measure the availability that may be extracted from a reservoir or energy flux and it indicates that spontaneous processes tend to consume this exergy. Joule effect, Foucault current, viscosity, turbulence, heat transfer and friction deteriorate the energy but unlike energy, exergy is not preserved during natural transformation. The idea of dissipation of exergy is directly related to idea of creation of entropy and irreversibility. The exergy is the part of the energy that is virtually convertible into work. This is a consequence of the second principle of thermodynamics. The first to introduce this concept is G. Gouy, who, in the late nineteenth century, defined the concept of exergy. Numerous studies give useful information for practitioners about the exergy efficiency of different types of systems, I quote here: [7] [8]. Professor V. Radcenko, former Doyen of the Faculty of Mechanics, at the Polytechnic's University of Bucharest, who was also my thesis' supervisor, has published numerous books on the exergy, in which I will quote only: [2] [3]. In one of the chapters of my Ph.D. thesis, which is entitled "Contribution to the Study of the Optimization of Air Conditioning Systems" [9], an exergetic analysis of the air conditioning facility was treated. We applied this exergetic analysis to a small power plant in the case of, the ZR22K3E Copeland Scroll (Figure 1), in order to improve energy efficiency, by determining energy balance and exergy balance in order to obtain an exergetic yield that will be compared to the degree of reversibility of the plant, thus allowing a qualitative measure of energy losses that degrade efficiency installation. The energy as well as the different quantities involved in determining the energy balance are obtained in the $\log \mathrm{P}$-h. Figure 2 diagram is presented in Table 1 . The exegetic balance of the installation shall be carried out after the completion of the energy balance which consists of determining and summing all the energy involved, namely:

- the work of compressor $\left|W_{\text {inst }}\right|$;

- heat losed to the condenser $\left|q_{c D}\right|$;

- cold thermal production $q_{o}$;

- heat absorbed $q_{s c}$ to the overheating [4] [5] [10].

To establish the exergetic balance sheet, one calculates all losses which appear during the transformations, namely:

- the losses due to the compression process $\pi_{i r C}$;

- the losses due to the relaxation process $\pi_{i r D}$;

- the losses due to the condensation process $\pi_{i r C d}$;

- the losses due to the spray process $\pi_{i r E v}$;

- the losses due to the overheating process $\pi_{i r S c}$ [10] [11] [12] [13].

The recognition of these losses can only be validated, if the degree of reversibility reached $\eta_{\text {rev }}$ and the report of $C O P_{\text {inst }}$ to $C O P_{c}$ of the Carnot cycle of the installation is equal to the performance achieved by the energetic carried out. These losses due to the process of each part of the installation can be analyzed in detail to improve the overall performance of the whole installation. Finally, it 
should be noted that in most of the works and documents relating to the exegetic analyzes of energy facilities that have been published so far do not have an experimental approach. It is with a purely pedagogical and didactic purpose that we have prepared a study on a practical case of a simple and usual installation.

\section{Materials and Method}

\subsection{Material}

The refrigeration system which is the subject of the exergetic analysis (Figure 1), is a designated refrigeration unit: ZR22K3E Copeland Scroll composed of a compressor, a condenser and an evaporator having a vaporization temperature of $\mathrm{T}_{0}=268 \mathrm{~K}$ and ambient temperature $\mathrm{T}_{\mathrm{a}}=305 \mathrm{~K}$.

\subsection{Method}

To calculate the exergy yield of the installation, it is first necessary to determine the characteristic quantities of the refrigeration cycle allowing the realization of the exergy balance which shows for each organ the loss that it generates.

- Determination of the dimension's characteristics of the cold cycle R134a

The coefficient of performance (C.O.P.) of the Carnot cycle, limited by the temperature $T_{a}$ and $T_{0}$, is determined by the following the relationship: [2] [3] [4]

$$
C O P_{c}=\frac{T_{0}}{T_{a}-T_{0}}
$$

The cycle in (Figure 2) show that the compressor sucks from overheated to state 1 . These vapors are then compressed during process $1-2$, performing a mechanical work that expresses itself through the relationship:

$$
\left|W_{\text {inst }}\right|=h_{2}-h_{1}[\mathrm{~kJ} / \mathrm{kg}]
$$

These vapors are transferred to the process 2-4 condenser, where they release the condensation heat expressed by the relationship:

$$
\left|q_{C D}\right|=h_{4}-h_{2}[\mathrm{~kJ} / \mathrm{kg}]
$$

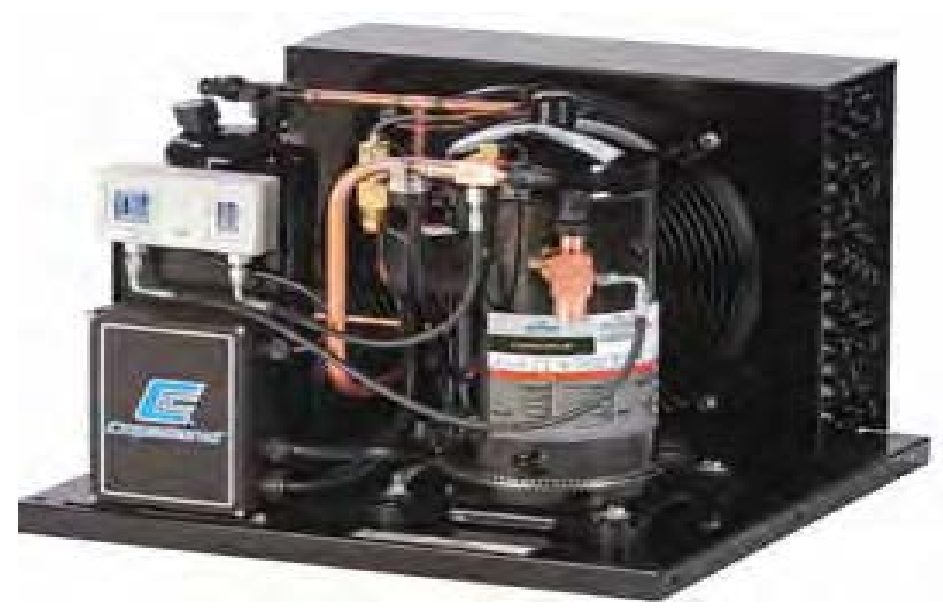

Figure 1. ZR22K3E Copeland scroll refrigerator group representation. 


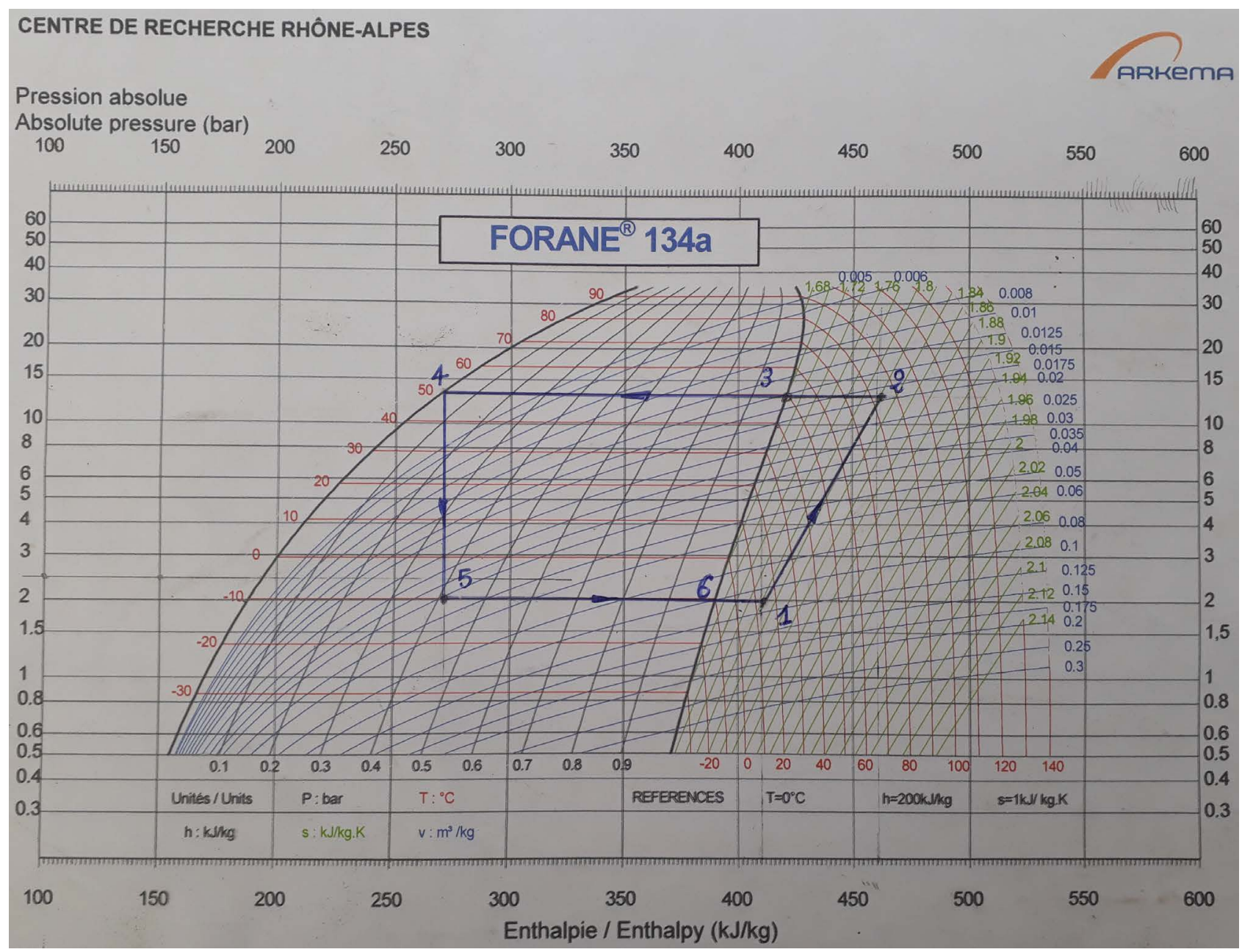

Figure 2. Representation on the LogP-h diagram of the ZR22K3E cold cycle.

In state 4 in liquid form, they enter the regulator process 4-5 and undergo relaxation. The process in the regulator is isenthalpic. After relaxation in the regulator, the vapors are sucked into evaporator process 5-6, in which the vaporization of the liquid that produces the cold effect expressed by the relationship occurs:

$$
q_{0}=h_{6}-h_{5}[\mathrm{~kJ} / \mathrm{kg}]
$$

The vapors are then overheated by the heat of overheating expressed by the relationship:

$$
q_{S C}=h_{1}-h_{6}[\mathrm{~kJ} / \mathrm{kg}]
$$

They will be sucked by compressor, process 6-1.

The Coefficient of Performance of the installation is determined by the relationship:

$$
C O P_{\text {inst }}=\frac{q_{0}}{\left|W_{\text {inst }}\right|}
$$

The degree of irreversibility through the relationship: 


$$
\eta_{\text {rev }}=\frac{C O P_{\text {inst }}}{C O P_{c}}[\%]
$$

The mechanical work of the Carnot cycle of the installation is calculated by the relationship:

$$
\left|W_{c}\right|=\frac{q_{0}}{C O P_{c}}=\left|W_{\text {inst }}\right|-\sum_{J=1}^{6} \pi_{J}
$$

where: $\sum_{J=1}^{6} \pi_{J}$, is the sum of the exergetic losses due to the irreversibility of the cold production system plant.

\section{- Calculation of the losses due to the irreversibility of cycle R134a}

During the process in the refrigeration system, a number of irreversibility losses appear which can be calculated by the following relationships: [7] [8] [10]

- Loss of exergy during the relaxation process:

$$
\pi_{i r D}=T_{a} \Delta S_{i r D}=T_{a}\left(S_{5}-S_{4}\right)[\mathrm{kJ} / \mathrm{kg}]
$$

Then the weight of exergetic loss during the relaxation process will be:

$$
\bar{\pi}_{i r D}=\frac{\pi_{i r D}}{\left|W_{c}\right|} \times 100(\%)
$$

- Loss of exergy during compression process:

$$
\pi_{i r C}=T_{a} \Delta S_{i r C}=T_{a}\left(S_{2}-S_{1}\right)[\mathrm{kJ} / \mathrm{kg}]
$$

Then the weight of exergetic loss during the compression process will be:

$$
\bar{\pi}_{i r C}=\frac{\pi_{i r C}}{\left|W_{c}\right|} \times 100(\%)
$$

- Loss of exergy during the heat transfer process in the condenser:

$$
\pi_{i r C d}=\left|q_{C d}\right|-T_{a}\left|\Delta S_{C d}\right|[\mathrm{kJ} / \mathrm{kg}]
$$

Then the weight of exergetic loss during the condensation process will be:

$$
\bar{\pi}_{i r C d}=\frac{\pi_{i r C d}}{\left|W_{c}\right|} \times 100(\%)
$$

- Loss of exergy during overheating process:

$$
\pi_{i r S c}=T_{a} \Delta S_{S c}-q_{S c}
$$

Then the weight of exergetic loss during the overheating process will be:

$$
\bar{\pi}_{i r S c}=\frac{\pi_{i r S c}}{\left|W_{c}\right|} \times 100(\%)
$$

- Loss of exergy during the heat transfer process in the evaporator:

$$
\pi_{i r E v}=T_{a} \Delta S_{E v}-q_{0}[\mathrm{~kJ} / \mathrm{kg}]
$$

Weighting of exergetic loss during the process of heat transfer to the evaporator:

$$
\bar{\pi}_{i r E v}=\frac{\pi_{i r E v}}{\left|W_{c}\right|} \times 100(\%)
$$


Table 1. ZR22K3E group refrigeration cycle characteristic point status parameters.

\begin{tabular}{cccccc}
\hline Point & $\begin{array}{c}\text { Pressure } \\
{[\mathrm{bar}]}\end{array}$ & $\begin{array}{c}\text { Température } \\
{\left[\mathrm{t}^{\circ} \mathrm{C}\right]}\end{array}$ & $\begin{array}{c}\text { Specific Volume } \\
{\left[\mathrm{dm}^{3}\right]}\end{array}$ & $\begin{array}{c}\text { Enthalpy } \\
{[\mathrm{kJ} / \mathrm{kg}]}\end{array}$ & $\begin{array}{c}\text { Entropy } \\
{[\mathrm{kJ} /(\mathrm{kg} . \mathrm{K})]}\end{array}$ \\
\hline 1 & 2.43 & 12.00 & 89.67 & 410.26 & 1.7829 \\
2 & 13.18 & 80.62 & 18.39 & 458.69 & 1.8104 \\
3 & 13.18 & 50.00 & 15.10 & 423.38 & 1.7071 \\
4 & 13.18 & 50.00 & 0.91 & 271.52 & 1.2367 \\
5 & 2.43 & -5.00 & 32.48 & 271.52 & 1.2672 \\
6 & 2.43 & 2.00 & 85.65 & 401.59 & 1.7519 \\
\hline
\end{tabular}

\section{- Calculation of the exegetics' performance}

Exegetic's performance highlights both qualitative and quantitative aspects of the energies involved in the processes of the refrigerant installation. He expresses himself through the relationship: [7] [10] [11]

$$
\eta_{e x}=100-\sum_{J=1}^{6} \pi_{J}
$$

Exergetic's performance must be approximately equal to the degree of irreversibility:

$$
\eta_{\text {rev }}=\eta_{\text {ex }}
$$

\section{Results and Discussion}

In order to establish the energy balance, it is assumed that the sum of energy absorbed by the evaporator, the overheating energy and the energy absorbed by the compressor is equal to the energy released to the condenser. The energy balance in (Figure 3) and in Table 2 shows that the compressor has required minimal mechanical work $\left|W_{\text {inst }}\right|=48.04[\mathrm{~kJ} / \mathrm{kg}]$, to achieve refrigeration production $q_{0}=130.07[\mathrm{~kJ} / \mathrm{kg}]$, taking into account overheating energy $q_{S C}$. Which work corresponds, for a given coefficient of performance, C.O. $P_{\text {inst }}=7.6$ to the heat $\left|q_{C D}\right|=186.78[\mathrm{~kJ} / \mathrm{kg}]$, evacuated by the condenser. It should be noted that, at this stage, it is not sufficient to assess the performance and quality of the process carried out by the installation, or to make an analysis, because the energy balance only shows the quantitative aspect of energies involved [2] [7] [13].

In Figure 3 and Table 3, the drill balance expressed by the relationship: $\left|W_{\text {inst }}\right|=\left|W_{c}\right|-\sum_{J=1}^{6} \pi_{J}$, takes into account both the qualitative and quantitative aspects of the energies involved in the installation processes of refrigeration production. Indeed, the degree of reversibility as shown in Table 2 is approximately equal to the actual yield achieved unchanged $\eta_{e x}=100-\sum_{J=1}^{6} \pi_{J}$, which means that the difference the amount of energy involved and the losses due to irreversibilities is equivalent to the fraction of energy that differentiates it from the ideal cycle of Carnot [7] [10] [11] [12].

Figure 3 explicitly highlights the energy-exergy balance, which highlights energy losses in each part of the system and thus allows them to be identifified 


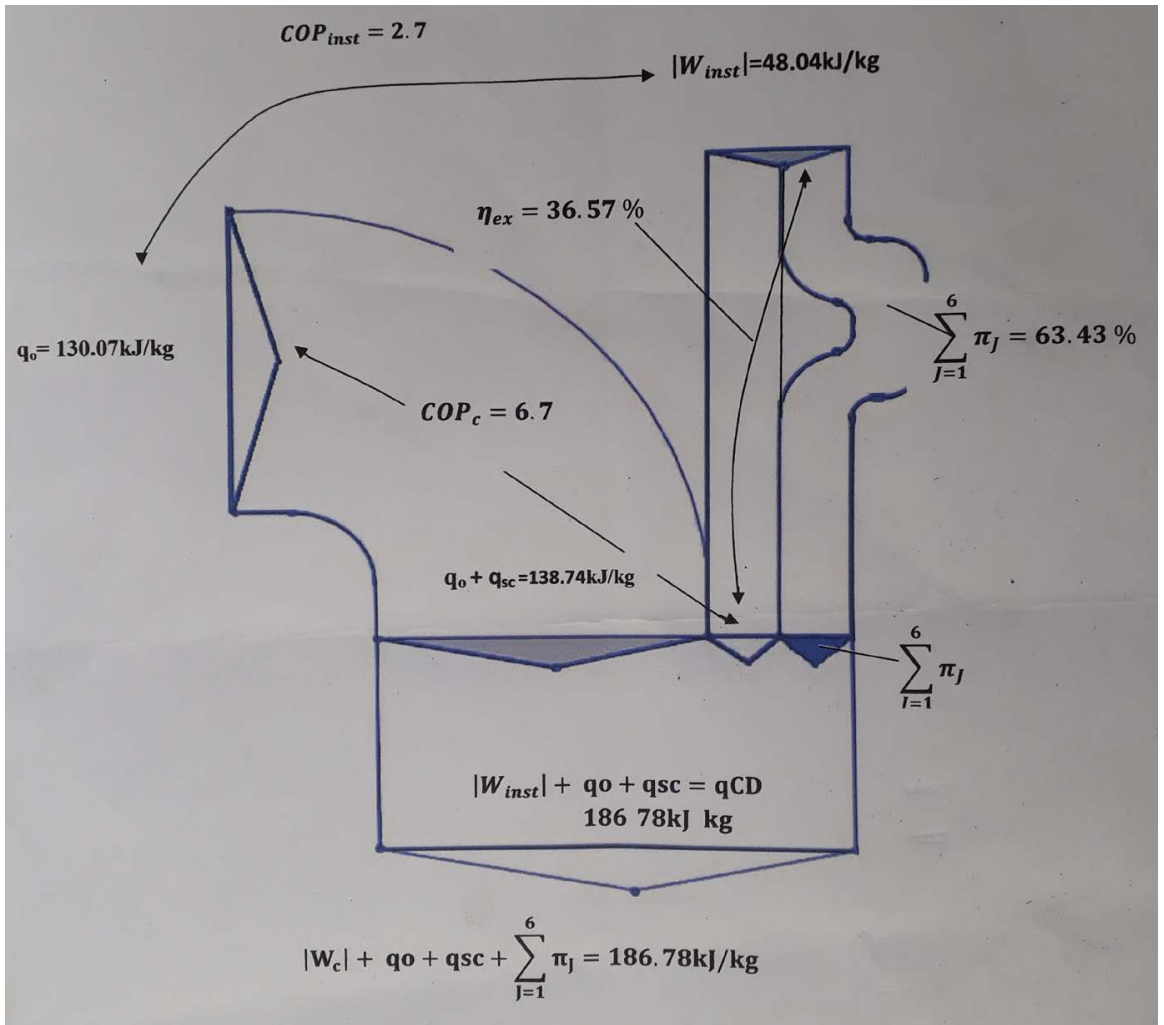

Figure 3. Energy-exergetic balance of the refrigeration unit ZR22K3E Copeland Scroll.

Table 2. Characteristic dimensions of the cooling cycle of the ZR22K3E installation.

\begin{tabular}{lccccccc}
\hline C.O.P & $\begin{array}{c}\left|W_{\text {inst }}\right| \\
{[\mathrm{kJ} / \mathrm{kg}]}\end{array}$ & COP $_{\text {inst }}$ & $\begin{array}{c}q_{0} \\
{[\mathrm{~kJ} / \mathrm{kg}]}\end{array}$ & $\begin{array}{c}\left|q_{C D}\right| \\
{[\mathrm{kJ} / \mathrm{kg}]}\end{array}$ & $\begin{array}{c}q_{s c} \\
{[\mathrm{~kJ} / \mathrm{kg}]}\end{array}$ & $\begin{array}{c}\left|W_{c}\right| \\
{[\mathrm{kJ} / \mathrm{kg}]}\end{array}$ & $\begin{array}{c}\eta_{\text {rev }} \\
{[\%]}\end{array}$ \\
\hline 7.20 & 48.04 & 2.70 & 130.07 & 186.78 & 8.67 & 19.41 & 37.50 \\
\hline
\end{tabular}

Table 3. Exergetic losses due to the internal and external irreversibilities of the ZR22K3E installation.

\begin{tabular}{ccccccc}
\hline $\bar{\pi}_{i r D}[\%]$ & $\bar{\pi}_{i r C}[\%]$ & $\bar{\pi}_{i r C D}[\%]$ & $\bar{\pi}_{i r S C}[\%]$ & $\bar{\pi}_{i r E v}[\%]$ & $\eta_{e x}[\%]$ \\
\hline 19.36 & 17.46 & 24.60 & 1.63 & 0.38 & 36.57 \\
\hline
\end{tabular}

and analyzed for possible improvements. When the percentage of one of the losses due to the irreversibilities increases, the coefficient of performance of the installation $C O P_{i n s t}=2.7$ is affected. This coefficient of performance moves away from the reference one of the Carnot's cycle and the exergy efficiency decreases [10] [11]. For very high loss percentages, the installation nevertheless produces cold with much higher energy consumption.

\section{Conclusion}

The results of this analysis are in fact consistent with the condition, that the exergetic performance, which is: 36.57 [\%] and it is approximately equal to the degree of irreversibility which is 37.50 [\%]. This method can be used to point out 
subassemblies that perform less well and then try to analyze the reason for the lack of performance of each process. We have identified the following losses: the loss in the compressor is 17.46 [\%], the loss in the evaporator is 0.38 [\%], the loss in the overheating is 1.63 [\%], the loss in the regulator is 19.36 [\%], the loss in the condenser is 24.60 [\%]. The identification of losses helps to rationalize energy resources and also reduce the environmental impact of these resources into the atmosphere. It should also be noted that the analysis was carried out on a new installation. If the analysis is carried out on a facility that has already been in operation for some time, on the one hand, the losses will be very high and on the other hand the economic losses will become noticeable and significant due to or interest in an exergetic analysis. This analysis shows that the losses are greater in the old installation. The size of the data involved in the exergy requires a numeric treatment of all incoming flows from the whole refrigeration system.

\section{Acknowledgements}

We would like to thank Professor Desire Lilonga-Boyenga of the National Polytechnic Graduate School of the University Marien Ngouabi for the assistance he has given us in carrying out this research.

\section{Conflicts of Interest}

The authors declare no conflicts of interest regarding the publication of this paper.

\section{References}

[1] Institut internationale du Froid (ED) (1990) Le froid et les CCF, compte rendu du colloque international de Bruxelle.

[2] Radcenco, V., Porneala, S. and Dobrobovicescu, A. (1983) Procese in installatii Frigorifice. Editura Didactice si Pedagogica, Bucarest.

[3] Radcenco, V. and Dobrobovicescu, A. (1987) Installatii Frigorifice si criogenice. Editura Tehnica, Bucarest.

[4] Feidt, M. (2009) Efficacité énergétique: Quels critères? Termotehnica, Bucarest.

[5] Rapin, P.J. and Jaquard, P. (1996) Installations Frigorifiques. PYC Edition, France.

[6] LE NOUVEAU POHLMANN (1083) Manuel Technique du Froid. PYC Edition, France.

[7] Canivet, Y. (2017) Analyse entropique et exergique des systèmes énergétiques par des représentations géométriques. Université de Nantere, Paris.

[8] Oignet, J. ( 2015) Approche exergétique d'un procédé de réfrigération. These de doctorat, Université Pierre et Marie Curie, Paris.

[9] Okotaka Ebale, L. (1994) Contribution à l'étude de l'optimisation des systèmes de conditionnement de l'air. Thèse de doctorat, Université Polytechnique de Bucarest.

[10] Malham, C.B. (2017) Méthodologie hybride (Exergie/Pinch) des procédés industriels. These de doctorat, Ecole Doctorale, Paris.

[11] Facts et Figures (2013) L'EXERGIE. ONEA Consulting, Paris.

[12] Bejan, A. (2002) Fundamentals of Exergy Analysis, Entropy Generation Minimization, 
and the Generation of flow Architecture. Inertnational Journal of Energy Research, 26, 0-43. https://doi.org/10.1002/er.804

[13] Kalogirou, S.A., Karellas, S., Badescu, I. and Braimakis, K. (2015) Exergy Analysis on Solar Thermal Systems: A Better Understanding of Their Sustainability. Renewable Energy, 85, 1328-1333. https://doi.org/10.1016/j.renene.2015.05.037

\section{Nomenclature}

$T_{a}=305:$ Temperature of the ambient environment $[\mathrm{K}]$;

$T_{0}=268$ : Evaporation temperature $[\mathrm{K}]$;

C.O.P $P_{\dot{c}}$ The Coefficient of Performance of the Carnot cycle;

$\left|W_{\text {inst }}\right|$ : Mechanical compression work $[\mathrm{kJ} / \mathrm{kg}]$;

$C O P_{\text {inst }}$ : Coefficient of Performance of the installation;

$\eta_{\text {rev }}:$ The degree of irreversibility [\%];

$\eta_{e x}$ : Exergetic performance [\%];

$q_{0}$ : Refrigerating production $[\mathrm{kJ} / \mathrm{kg}]$;

$\left|q_{c D}\right|:$ The amount of heat to be evacuated to the condenser $[\mathrm{kJ} / \mathrm{kg}]$;

$q_{s c}$ : Heat absorbed to the overheat $[\mathrm{kJ} / \mathrm{kg}]$;

$\left|W_{c}\right|$ : The mechanical work of the Carnot cycle of the installation $[\mathrm{kJ} / \mathrm{kg}]$;

$\sum_{J=1}^{6} \pi_{J}$ : Sum of the exergetic losses due to the irreversibility of the refrigeration installation $[\mathrm{kJ} / \mathrm{kg}]$;

$\pi_{i r D}$ : Loss of exergetic during the relaxation process $[\mathrm{kJ} / \mathrm{kg}]$;

$\bar{\pi}_{i r D}$ : Weighting of exergetic loss during the relaxation process [\%];

$\pi_{i r C}$ : Loss of exergetic during compression process [kJ/kg];

$\bar{\pi}_{i r C}$ : Weighting of exergetic loss during compression process [\%];

$\pi_{i r C d}:$ Loss of exergetic of heat transfer process in condenser $[\mathrm{kJ} / \mathrm{kg}]$;

$\bar{\pi}_{i r C d}$ : Weighting of exergetic loss during compression process [\%];

$\pi_{i r s c}:$ Loss of exergetic during overheating process $[\mathrm{kJ} / \mathrm{kg}]$;

$\bar{\pi}_{i r s c}$ : Weighting of exergetic loss during overheating process [\%];

$\pi_{i r E v}:$ Loss of exergetic of the heat transfer process in the evaporator $[\mathrm{kJ} / \mathrm{kg}]$;

$\bar{\pi}_{i r E v}$ : Weighting of exergy loss during the process of heat transfer to the evaporator [\%]. 